REVIEW / ARTÍCULO DE REVISIÓN

\title{
Microsphere: A Wander around Drug Delivery
}

${ }^{1}$ B.Pharm, Bharat Technology, Uluberia, Howrah - 711316, WB.

2B. Pharm, School Of Pharmacy, Techno India University, Salt Lake Sec-V, Kolkata - 700091, WB.

3 M.Pharm, Pharmaceutics, Gupta College of Technological Sciences, Ashram More, GT Road, Asansol - 713301, WB.

${ }^{4}$ Assistant Professor, Department Of Pharmaceutics, Radha Govind University, Ramgarh, Jharkhand.

Corresponding author: anirban.karmakar.ak@gmail.com

Abstract: Microspheres have free-flowing powder characteristics consisting of synthetic polymers and proteins with a particle size of 1-1000 $\mu \mathrm{m}$. Microsphere improves bioavailability, stability and targets the drug to a selected site at a predetermined rate. Sorts of microspheres are bioadhesive, floating, radioactive, polymeric, and biodegradable microspheres. Therefore, the array of practices for the groundwork of microspheres offers a chance to regulate drug administration properties and develop the therapeutic efficacy of a given drug. The microsphere is spherical microparticles \& is employed where predictable \& consistent particle area is vital. The microspheres have the drug located centrally within the particle encased within the unique polymeric membrane. The present review highlights various sorts of microspheres, different methods of preparation, their applications, and various parameters to gauge their efficiency. Microspheres have received much attention not just for prolonged release but also for targeted medicine. A systematic review of one of the most promising drug delivery systems should be easier to read than the medical research articles, as they target a wider audience. The systematic reviews of the microparticles conclude that spherical microspheres \& are accustomed to delivering the drug at the target site with specificity if modified and take care of the specified concentration at the location of interest without the untoward effects presented during a consistent therapy to help research and retrieval of health.

Key words: Microsphere, Microparticles, Ionotropic Gelation, Microsphere Formulation, Microsphere Evaluation, Review Microspheres.

\section{Introduction}

Microparticles drug delivery system is one of the processes to provide the sustained and managed to ship of medication to long periods, as small particles of solids or tiny droplets of beverages surrounded employing partitions of natural and artificial polymer films of various thickness and degree of permeability performing as a release charge controlling substance ${ }^{1}$. Originally practice of albumin microparticles in drug delivery systems was advised by Kramer in 1974². Microparticles are well-defined as particulate dispersions or solid particles by size in the range of $1-1000$ micrometer ${ }^{3}$ where the drug is dissolved and entrapped, encapsulated or attached to a microparticles matrix 4 . Varying upon the preparation method, microparticles, microspheres, or microcapsules can be gained $^{5}$. Microparticles are micrometric matrix systems and are efficiently sphere-shaped in shape ${ }^{6}$. Microparticles are the polymeric entities in which the drug is physically and homogeneously dispersed, whereas microcapsules are micrometric reservoir systems, and microcapsules may be globular or nonglobular in shape ${ }^{3}$. Microcapsules are structures in which the drug is limited to a hollow surrounded by an exclusive polymer membrane. Microcapsules size 100-150 micrometer ${ }^{7}$. The microencapsulation technology allows protection of medication from the environment, stabilization of sensitive drug substances, elimination of incompatibilities, or masking of unsightly flavor $^{8}$. Hence, they play an improved bioavailability of conven- tional drugs and minimize side effects. Treatment is restricted to solid consideration. A more comprehensive and far-reaching approach and venture are critically required for suitable countermeasures and readiness ${ }^{9}$. Microparticles are also a valuable way of turning in APIs, which might be pharmacological lively but are difficult to supply due to confined solubility in water. In such tablets, attaining high Cmax, Tmax and AUC is problematic. Consequently, a need exists for fast-release products containing those agents. Microparticles-based formulations can offer a steady drug awareness within the blood or target tablets to precise cells or organs ${ }^{10}$. In recent years biodegradable polymeric microparticles, mainly those coated with a hydrophilic polymer which includes polyethylene glycol, known as long-circulating particles, have been used as potential drug delivery devices for of their ability to distribute for a prolonged period objected to a particular organ, and their proficiency in delivering proteins, peptides and genes ${ }^{11}$.

Microparticles offer a way to supply macromolecules by spreading routes and efficiently managing the discharge of such pills or drugs ${ }^{12}$. Additionally, it can be used to ship vaccines and molecules inclusive of DNA for use in gene therapy. Macromolecules offer adequate safety of encapsulated marketers towards degradation, the opportunity of controlled and local shipping of the drug over intervals starting from a few hours to months, and smooth management. Controlled drug

Citation: Karmakar A, Dev Maity S, Barua S, Das R. Microsphere: A Wander around Drug Delivery. Revis Bionatura 2022;7(1). 13. http://dx.doi. org/10.21931/RB/2022.07.01.13

Received: 25 August 2021 / Accepted: 20 November 2021 / Published: 15 February 2022

Publisher's Note: Bionatura stays neutral with regard to jurisdictional claims in published maps and institutional affiliations. 
delivery structures could be instrumental in supplying the optimal therapy for a given drug molecule. Each drug has a distinguishing 'minimum effective concentration', below which no therapeutic effect is detected and a specific 'minimum toxic concentration' above which undesired side effects arise. The range between is so-called the 'therapeutic range' or 'therapeutic window. Varying upon the type of drug and biological factors, this therapeutic window could be thin ${ }^{5}$. The most advantageous effect of many clinical cares is obtained by keeping the drug attention inside the therapeutic variety over a sustained time frame ${ }^{5}$. Every scientist reconciles whether and what to decrypt and how to display it ${ }^{13}$. This is chiefly proper for potent drugs, together with anti-cancer drugs. Management of the entire drug dose straight away the use of conventional pharmaceutical dosage, the whole quantity is rapidly launched into the belly, absorbed into the bloodstream, and dispensed at some stage in the human frame. Therefore, the rate at which the drug is the movement website is often improved. Depending on the therapeutic range and dispensed dose, the risk of toxic side effects can be considerable.

The concentration decreases again as no continuous drug supply is provided, and the human body eliminates the active agent. This results in a shifting concentration of the drug levels in the plasma, and the therapeutic range is reached through a brief period ${ }^{14}$. This represents a pressing test to the pharmaceutical business to create practical conveyance frameworks for the proficient conveyance of this mind-boggling restorative in a naturally dynamic shape. Their need is the clinical and remedial districts has heightened the examination ${ }^{15}$. The hydrophilic and lipophilic drug may be fused or entrapped into moderately high-performance polymeric microparticles. Those styles of drug service structures have proved to be extra physic-chemically solid than liposomes both in vivo and throughout storage ${ }^{11}$. Pharmacy discipline plays a fundamental role in patient healthcare. It is a considerable discipline that is present worldwide. With the propagation of the Internet and the growth in computer technology and manufacturing, the ratio of price to performance decreases ${ }^{16}$. The work done would su- rely help in academic purpose and the reference to be used in the future development when all is said in done component of an expanded conveyance framework is progressively seen as a favorable answer for natural medications ${ }^{17}$.

\section{Drug Delivery Systems}

\section{Novel drug delivery system}

Several drug delivery and drug-directed systems are developed to minimize drug degradation, drug adverse effects, and surge the drug bioavailability (quantity of drug available at a site targeted section). Site precise drug delivery may be either active or passive procedure ${ }^{18}$.

\section{Drug Delivery Carriers}

Colloidal drug carrier techniques such as micellar solutions, liquid crystal dispersions, vesicles, and nanoparticle dispersions comprising tiny particles of 10-400 nm diameter show great promise as drug delivery systems. When budding these formulations, the goal is to gain systems with optimized drug loading and release properties, extended shelf-life and low toxicity ${ }^{19}$.

\section{Micelles}

Micelles formed by self-assembly of amphiphilic block co-polymers (5-50 nm) in aqueous solutions are of great interest for drug delivery applications ${ }^{20}$. The drug or the medication may be physically entrapped in the middle of block copolymer micelles and transported at concentrations that may exceed their intrinsic water- solubility ${ }^{21,22}$.

\section{Liposome}

Liposome serves lipoidal vesicles (lipid bilayer), which serve as drug providers to improve the shipping of pharmaceutical drugs ${ }^{23}$. Liposomes are small lipoidal vesicles enclosing an aqueous solution inner a hydrophobic membrane. To deliver the molecules to the focused website online, the lipid bilayer

\begin{tabular}{|c|c|c|c|}
\hline \multicolumn{4}{|c|}{ Demographic characters } \\
\hline \multirow{2}{*}{ variant } & groups & frequency & percent \\
\hline \multirow{2}{*}{ gender } & male & 27 & 45.0 \\
\cline { 2 - 4 } & female & 33 & 55.0 \\
\cline { 2 - 4 } & Total & 60 & 100.0 \\
\hline \multirow{2}{*}{ emplonce } & Urban & 34 & 56 \\
\cline { 2 - 4 } & Rural & 26 & 43 \\
\cline { 2 - 4 } & Total & 60 & 100 \\
\hline & employ & 16 & 26.7 \\
\cline { 2 - 4 } & Not employ & 44 & 73.3 \\
\cline { 2 - 4 } & Total & 60 & 100 \\
\hline
\end{tabular}

Table 1. The demographic characters. 


\begin{tabular}{|c|c|c|c|c|c|c|}
\hline \multirow{2}{*}{ N=60 } & \multicolumn{3}{|c|}{$\begin{array}{c}\text { Intervention group } \\
\text { mean }\end{array}$} & \multicolumn{3}{c|}{$\begin{array}{c}\text { Control group } \\
\text { mean }\end{array}$} \\
\hline & before & after & p-value & before & after & p-value \\
\cline { 2 - 7 } & 85.75 & 84.85 & $<0.0001$ & 86.30 & 87.08 & $<\mathbf{0 . 0 0 0 1}$ \\
\hline weight & 103.97 & 101.62 & $<0.0001$ & 106.30 & 106.36 & $\mathbf{0 . 8 9 5}$ \\
\hline Waist circumference & 31.11 & 30.40 & $<0.0001$ & 32.27 & 32.55 & $<\mathbf{0 . 0 0 0 1}$ \\
\hline B.M.I. & 176.93 & 141.4 & $<0.0001$ & 183.36 & 192.40 & $\mathbf{0 . 0 3 5}$ \\
\hline FBS & & & & & & \\
\hline
\end{tabular}

${ }^{*}$ Significant $\mathrm{P}$ value $<0.05$

Table 2. Comparisons characteristics of the study group before and after the intervention.

\begin{tabular}{|c|c|c|c|}
\hline $\mathbf{N = 6 0}$ & $\begin{array}{c}\text { Intervention } \\
\text { group } \\
\text { Mean } \\
\text { SD }\end{array}$ & $\begin{array}{c}\text { Control group } \\
\text { Mean }\end{array}$ & P-Value \\
& -0.89 & SD & \\
\hline Weight change & \pm 0.79 & 0.79 & $<\mathbf{0 . 0 0 0 1}$ \\
\hline Waist & -2.35 & 0.07 & $<\mathbf{0 . 0 0 0 1}$ \\
circumference & \pm 1.16 & \pm 2.75 & \\
changes & -0.71 & 0.28 & $<\mathbf{0 . 0 0 0 1}$ \\
\hline BMI change & \pm 0.37 & \pm 0.88 & \\
\hline FBS change & -35.07 & 9.03 & $<0.0001$ \\
\hline
\end{tabular}

\footnotetext{
${ }^{*}$ Significant $\mathrm{P}$ value $<0.05$
}

Table 3. Shows the difference between the intervention and the control group in the mean change of the characteristics study group.

can fuse with different bilayers, including the cell membrane; for that reason, liposomes act as drug providers for drug shipping for drug delivery ${ }^{23}$.

\section{Hydrogels}

Hydrogels are three-dimensional cross-linked water-soluble polymers ${ }^{24}$. various combinations of polymers are formulated for novel drug delivery devices as novel drug delivery systems ${ }^{23}$. numerous tablets formulated as hydrogels consist of Riboflavin, Salicylic acid, Simvastatin 22,23 .

\section{Nano Particles}

Nanoparticles are amorphous or crystalline compounds starting from 10-200 nm, which are novel drug gadgets used for novel drug delivery systems ${ }^{25}$. Nanoparticles adsorb or encapsulate the drug, thus protecting against chemical or enzymatic degradation ${ }^{26,27}$. Diverse Nano gadgets for drug shipping include Nanotubes, quantum dots, Nanorobots, den dimers, Nanowires, Nanoshells and Nanopores ${ }^{23}$. The discharge of the drug from the formulation is by controlled diffusion. Thus the discharge of the drug happens from the core, across the polymer matrix or membrane ${ }^{23}$. Hence, the membrane acts as a barrier for drug release ${ }^{28}$. therefore solubility and diffusivity of drug in polymer membrane will become the figuring out element for drug release ${ }^{23,29}$.

\section{Materials Used For Preparation Of Microsphere}

Microspheres used typically are made with polymers that have manifold blessings. Those are reliable means to supply the drug to the target website online with specificity if changed and keep the desired awareness on the web page of the hobby without untoward results ${ }^{30}$. Strong biodegradable microspheres have the capacity during the particle-matrix for the controlled launch of drug ${ }^{31}$. Microspheres received much attention now for extended-release and for concentrating on anti-cancer drugs to the tumor ${ }^{32}$. the dimensions, surface fee, and floor hydrophilicity of microspheres have been attained to be crucial in regulating the fate of particles in vivo studies at the macrophage uptake of microspheres have verified their ability in concentrated on tablets to pathogens residing intracellularly ${ }^{33}$. Microspheres made with polymers are classified into two types:

\section{Synthetic Polymer}

Synthetic polymers are divided into two types.

\section{Non-biodegradable polymers}

Some examples are Polymethyl methacrylate (PMMA) and Acrolein Glycidyl methacrylate and Epoxy polymers.

\section{Biodegradable polymers}

Some examples being Lactides as well as Glycolides with their co-polymers, Poly-alkyl cyano acrylates and Poly-anhydrides.

\section{Natural polymers}

Natural polymers gained from diverse sources like proteins, carbohydrates and chemically modified Carbohydrates, 
Proteins like Albumin, Gelatin, and Collagen. Carbohydrates like Agarose, Carrageenan, Chitosan, and Starch. Chemically modified carbohydrates like Poly dextran, Poly starch ${ }^{34}$. The health benefits are rewarding which gives an extra boost to use this items on daily basis keeping in check the over consumption ${ }^{35}$.

\section{Types Of Microspheres}

\section{Bio adhesive microspheres}

Adhesion may be defined as sticking the drug to the membrane by using the sticking belongings of the water-soluble polymers ${ }^{36}$. Adhesion of drug shipping device to the mucosal membrane consisting of buccal, rectal, ocular, and nasal can be labeled as bio adhesion ${ }^{37}$. These microspheres show off a prolonged residence time at the website of software and motive intimate contact with the absorption web page, producing higher healing motion ${ }^{38}$.

\section{Magnetic microspheres}

This kind of delivery system could be very a great deal essential which localizes the drug to the sickness or disease site $^{39}$. This large amount of freely circulating drug can be replaced via a smaller quantity of magnetically centered drug ${ }^{39}$. Magnetic carriers hold magnetic responses to a magnetic area from integrated materials used for magnetic microspheres like chitosan, dextran ${ }^{40}$. Therapeutic or healing magnetic microspheres are used to supply chemotherapeutic agents to liver tumors ${ }^{40}$. Drugs like proteins and peptides also can be targeted through this system ${ }^{41}$. Diagnostic microspheres, used for imaging liver metastases and also can be used to extricate bowel loops from other abdominal systems by using forming nano-sized debris supramagnetic iron oxides ${ }^{42}$

\section{Floating microspheres}

In floating kinds, the majority density is much less than the gastric fluid and stays buoyant within the stomach without affecting gastric emptying rate ${ }^{43}$. The drug is launched slowly on the favored charge, and the gadget is determined to be floating on gastric content material, increasing gastric juice and increasing fluctuation in plasma ${ }^{44}$. Moreover, it also reduces the possibility of dose dumping. It produces a prolonged therapeutic impact and consequently reduces dosing frequencies ${ }^{37}$. Drug (ketoprofen) is given within the shape of floating microspheres ${ }^{42,45}$.

\section{Radioactive microspheres}

Radioembolization treatment microspheres sized 10-30 $\mathrm{nm}$ are more significant than the capillaries' diameter and get tapped inside the first capillary bed once they come across. They may be injected into the arteries that cause them to tumors of the hobby, so these kinds of conditions radioactive microspheres deliver excessive radiation doses to the targeted regions without unfavorable the everyday surrounding tissues $^{44}$. It varies from drug delivery systems because radioactivity is not discharged from microspheres but acts from within a typical radioisotope distance and atypical kinds of radioactive microspheres are a emitters, $\beta$ emitters, $y$ emitters ${ }^{44}$.

\section{Polymeric microspheres}

The distinctive kinds of polymeric microspheres may be classified as biodegradable and synthetic polymeric microspheres ${ }^{42,44,46}$.

\section{Biodegradable polymeric microspheres}

Natural polymers such as starch are worked with the concept that they are biodegradable, biocompatible, and also bioadhesive in the environment. Biodegradable polymers prolong the house time when touched with mucous membrane due to its high degree of swelling belongings with an aqueous medium, resulting in gel formation. The rate and quantity of drug release are measured using the polymer's concentration and the release pattern in a sustained way. The primary disadvantage is that in scientific use, drug loading performance of biodegradable microspheres is complicated and challenging to control the drug release ${ }^{47}$, but it provides a wide range of applications in the microsphere-primarily based treatment ${ }^{44}$.

\section{Synthetic polymeric microspheres}

Synthetic polymeric microspheres are broadly utilized in medical utility; moreover, that extensively utilized as a bulking agent, fillers, embolic particles, drug delivery vehicles ${ }^{48}$ and proved to be safe and biocompatible, but the focal disadvantage of this kind of microspheres tends to migrate away from the injection site and lead to embolism, potential risk, and further organ damage $e^{44,46}$.

\section{Preparation Of Microspheres}

\section{Ionotropic gelation technique}

The gelation technique has been enhanced through several inspired methodological modifications ${ }^{49}$. Ionotropic gelation via electrospraying and spinning disc processing produces nanoparticles with a more uniform distribution. Hydrophobic and hydrophilic drugs can be encapsulated with high efficiency by emulsification followed by ionic gelation ${ }^{49}$. Ionotropic gelation is based on the competence of polyelectrolytes to cross-link in the authority of counter ions to form hydrogels ${ }^{50}$. The natural polyelectrolytes inspite, having a property of coating on the drug core and acting as release rate retardants, contains certain anions on their organic structure. These anions form a meshwork structure by combining with the polyvalent cations and inducing gelation by binding mainly to the anion blocks ${ }^{51,52}$.

\section{Single Emulsion Method}

The microparticulate carriers of the natural polymers, carbohydrates, \& proteins are prepared. The microparticulate carriers of natural polymers like proteins and carbohydrates are prepared by one emulsion technique ${ }^{36,53-55}$. The natural polymers are dissolved or dispersed during an aqueous medium followed by dispersion in a non-aqueous medium like oil. Next, cross-linking of the dispersed globule is administered. The cross-linking is often achieved through warmth or using chemical cross-linkers. The chemical cross-linking agents used are formaldehyde, glutaraldehyde, and acid chloride. Heat denaturation isn't suitable for thermolabile substances. Chemical cross-linking suffers the disadvantage of excessive exposure of active ingredients to chemicals added during preparation and then subjected to centrifugation, washing, and separation. The character of the surfactants wont to stabilize the emulsion phases can significantly influence the dimensions, surface morphology, size distribution, drug loading and release, and bio performance of the ultimate product. Schematic description of the Single Emulsion Method is given in Fig No. 1.

\section{Double Emulsion Method}

This method of microspheres preparation involves the formation of multiple emulsions or double emulsions of type 
$\mathrm{w} / \mathrm{o} / \mathrm{w}$ and is the most acceptable match to the water-soluble drugs, peptides, proteins, and vaccines. This method is often used with both naturals also as synthetic polymers. The aqueous protein solution is dispersed within the lipophilic organic continuous phase. This protein solution may enclose the active constituents. Schematic description of the Double Emulsion Method is given in Fig No. 236,53-55.

\section{Polymerization Method}

It is administered with the aid of the usage of exceptional techniques as bulk, suspension, precipitation, emulsion, and micellar polymerization methods. In bulk, a monomer or an aggregate of monomers alongside the initiator or catalyst is typically heated to initiate polymerization. The polymer so obtained could also be molded as micro-spheres. Schematic description of the Polymerization Method is given in Fig No. $3^{36,54}$.

\section{Phase Separation and Coacervation Method}

This process is predicated on the principle of decreasing the polymer's solubility within the organic phase, which affects the formation of a polymer-rich phase called the coacervates. During this method, drug particles are dispersed during a polymer solution, and an incompatible polymer is brought to the device, making the primary polymer for the section separation. Schematic description of the Phase Separation and Coacervation method is given in Fig No. $4^{36,53-55}$.

\section{Spray Drying and Spray Congealing}

These methods have supported drying the mist of polymer and drugs within the air. Depending upon removal of the solvent or cooling of the answer, these two processes are named spray drying and spray congealing. Microparticles are separated from the recent air by the cyclone separator while

(Stirring, Sonication)

\section{Dispersion In Organic Phase Oil}

Microsphere In Organic Phase

Microsphere In Organic Phase

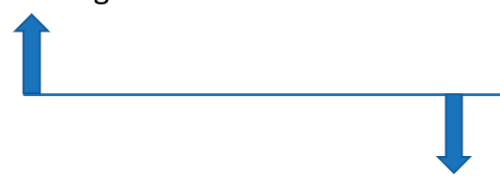

Microsphere

Figure 1. Single Emulsion method.

\section{Aqueous Solution Of Polymer +Drug}

\section{First Emulsion}

(Addition of Aqueous Solution of PVA)

\section{Multiple Emulsion}

(Addition of Large Aqueous Phase)

Microsphere in Solution

(Separation, Washing, Drying)

Microsphere

Figure 2. Double Emulsion method. 
the traces of solvent are eliminated using vacuum drying. One of the principal advantages of the technique is the feasibility of operation below aseptic situations ${ }^{36,53-55}$. The spray drying process is employed to encapsulate diverse penicillins. Thiamine mononitrate and sulpha ethylthiadiazole are encapsulated inside the mixture of mono and di-glycerides of stearic acid and palmitic acid using spray congealing. However, very speedy solvent evaporation results in the formation of porous microparticles. Schematic description of the Spray Drying and Spray Congealing method is given in Fig No. 5.

Other techniques are Wax Coating and Hot melt method, Air Suspension, Solvent Extraction, Precipitation, Freeze Drying ${ }^{56}$.

\section{Methods Of Preparation Of Microspheres by lonotropic \\ Gelatin Technique}

The microsphere of the test drug is prepared by ionotropic gelation technique using different proportions of polymers (sodium alginate and guar gum). Sodium alginate was dissolved in distilled water $(10 \mathrm{ml})$ in desired concentration and heated to make a liquid solution. Heated the desired quantity of guar gum in $10 \mathrm{ml}$ of water, mixed the sodium alginate solution, and prepared the polymer solution. Then the drug is brought into the polymer answer. Make five extraordinary types of formula in line with the ratio of Sodium Alginate: Guar gum is $1: 1,2: 1,3: 1,4: 1,5: 1$. The gelation medium became prepared by dissolving calcium chloride (five $\% \mathrm{w} / \mathrm{v}$ ). The homogenous alginate solution turned into extruded using a $21 \mathrm{G}$ syringe needle into the gelation medium. The space among the threshold of the needle and plane of gelation medium changed into about $10 \mathrm{cms}$. The gel microspheres shaped have been left in the answer with mild stirring for 30 min at room temperature to improve mechanic strength ${ }^{57}$. After that, microspheres are gathered and washed with distilled water two times, dried at room temperature for 24 hours, and stored in desiccators ${ }^{58,59}$. Gels are well known to depend on solvents and preparation methods. For example, PVA hydrogels prepared with freethaw cycling show exciting transparency features and a high modulus ${ }^{60}$.

\section{Evaluation Study Of Microspheres}

\section{Particle Size Analysis}

Microspheres were separated into different size fractions by sieving for 10 minutes using a mechanical shaker (Geologists Syndicate Pvt Ltd, India) containing standard sieves

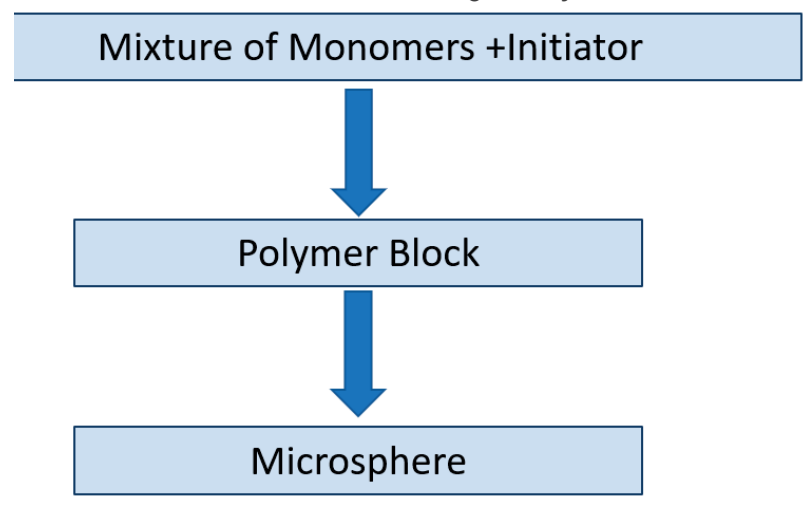

Figure 3. Polymerization method.

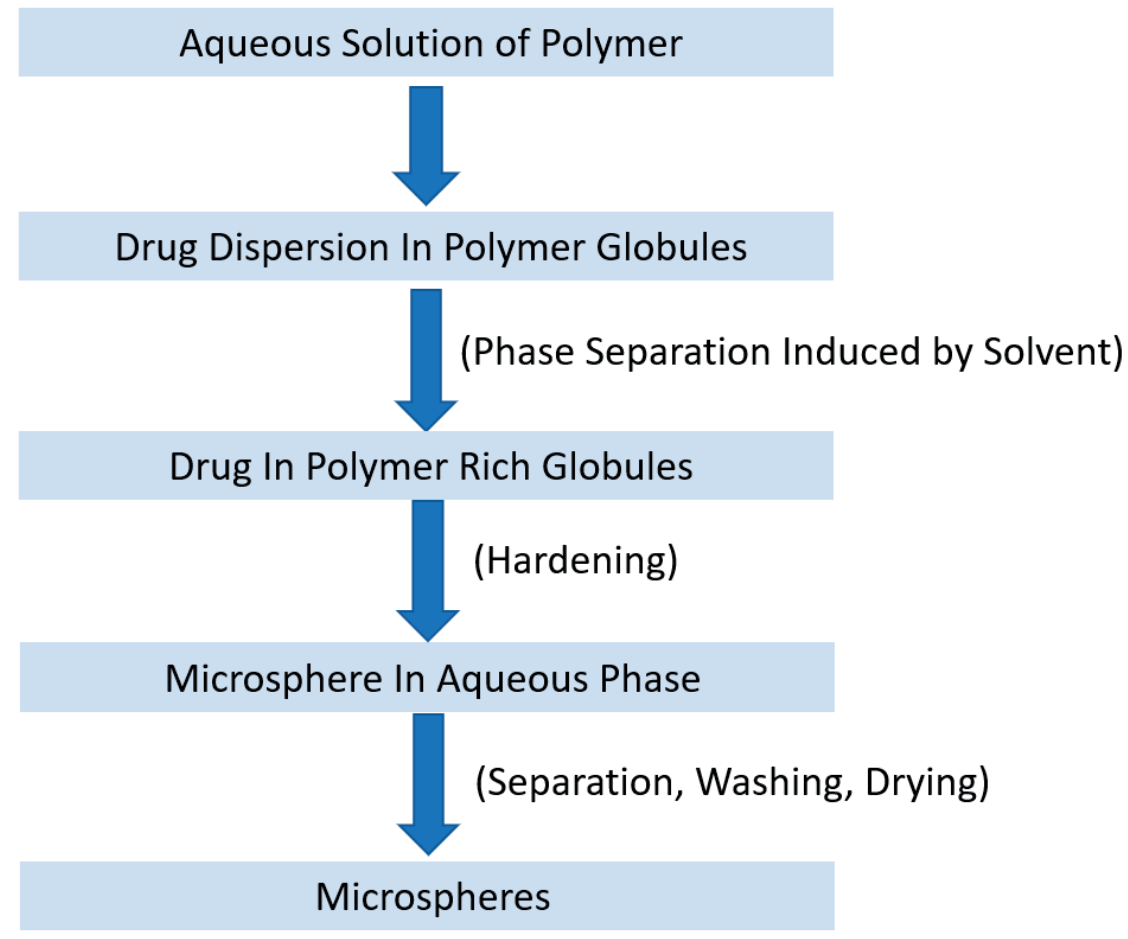

Figure 4. Phase Separation and Coacervation method. 


\section{Polymer is dissolved in Volatile Organic Solvent}<smiles>[AlH2]</smiles>

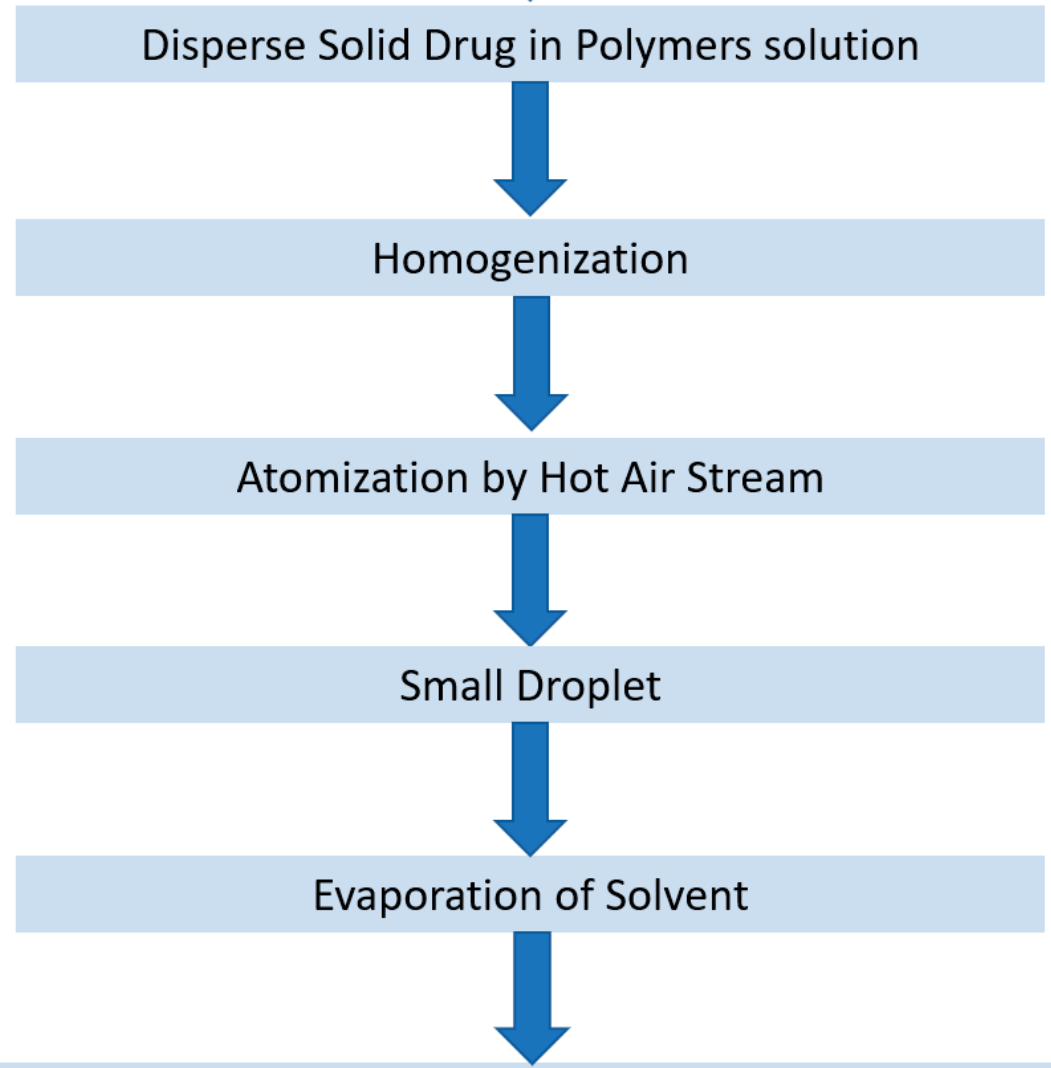

\section{Separation Of Microsphere And Vacuum Drying To Remove Traces Of Solvent}

Figure 5. Spray Drying and Spray Congealing.

having a mesh size of $\neq 16, \neq 18$, and $S S \neq 25$. The particle size distribution of the microspheres for all the formulations was determined, and the mean particle size of microspheres was calculated using the following formula ${ }^{61}$. Mean particle size $=\Sigma$ (mean particle size of the fraction $\times$ weight fraction) $/ \sum$ (weight fraction). Scanning Electron Microscopy is generally used to determine the particle's size and shape. The particle size can be determined by using light electron microscopy ${ }^{29,62}$.

\section{Surface morphology}

The samples for the SEM evaluation had been prepared with the aid of sprinkling the microspheres on one facet of the adhesive stub. Then the microspheres were blanketed with gold earlier than microscopy. Finally, the morphology and size of the microspheres had been observed with the scanning electron microscope (FEl Quanta- 2 hundred MK2, Netherlands) ${ }^{63}$.

\section{Drug entrapment efficiency, drug loading}

The amount of drug present in the Sodium Alginate and Guar Gum microspheres can be determined by taking the acknowledged quantity of microspheres wherein $100 \mathrm{mg}$ of the drug needs to be present theoretically ${ }^{64}$. Then, the microspheres were beaten, and the powdered microspheres were taken and dissolved in one hundred $\mathrm{ml}$ of phosphate buffer ( $\mathrm{pH} 7$.four) solution and stirred for 15 minutes with a c program language period of five mins and allowed to hold for twenty-four hours.
Then the solution was filtered through Whitman No.1 filter paper. Then the absorbance became measured spectro-photometrically at 320nm in opposition to phosphate buffer $\mathrm{pH} 7$. four) answer as clean with the help of UV double beam spectrophotometer, and concentrations had been determined by using the simultaneous equation: $\mathrm{Y}=\mathrm{mx}+\mathrm{c}$

DEE (\%) $=$ [Experimental drug Content / Initial Drug Content into the Formulation] $\times 100$

Drug Loading $(\%)=[\mathrm{Qm} / \mathrm{Wm}] \times 100^{10}$

Where, $\mathrm{Wm}=$ weight of the microspheres;

$\mathrm{Qm}=$ quantity of the drug present in the microspheres

\section{FTIR Studies}

The infrared (IR) spectra were recorded using an FTIR spectrophotometer (Perkin Elmer Spectrum GX) by the $\mathrm{KBr}$ pellet in the wavelength region between 4000 and $400 \mathrm{~cm}$ $1^{65}$. The spectra obtained for metronidazole and physical mixtures of metronidazole with polymers were compared to check the compatibility of the drug with polymers 62,64 .

\section{In vitro drug release study}

Dissolution studies were performed using an automated assembly comprising a dissolution bath (Pharmatest PTW III) and a UV visible spectrophotometer. For the first series of experiments, either $125 \mathrm{mg}$ of drug or weighed quantities of microspheres containing $100 \mathrm{mg}$ of test drug were placed in 
six separate 1-liter containers containing aqueous phosphate buffer ( $0.2 \mathrm{M}$ monobasic and $0.2 \mathrm{M}$ dibasic sodium phosphate mixed to solve with $\mathrm{pH} 8$ ). For the second series of experiments, dissolution media comprised five different buffer solutions, all prepared at $\mathrm{pH} 8$, incorporating a range of cations and anions. The buffers consisted of the following pairs of compounds titrated together to achieve $\mathrm{pH} 8$ solutions at $37^{\circ} \mathrm{C}$ : $0.2 \mathrm{M}$ monobasic and $0.2 \mathrm{M}$ dibasic sodium phosphate, $0.2 \mathrm{M}$ monobasic and $0.2 \mathrm{M}$ dibasic potassium phosphate, 0.1 $\mathrm{M}$ citric acid and $0.2 \mathrm{M}$ dibasic sodium phosphate, 0.1 M MOPS and 0.1 M MOPS sodium salt and finally, 0.1 M tris and 0.1 M hydrochloric acid. Finally, for the third series of experiments, drug release studies were conducted for test drugs contained within stearic acid microspheres using a sodium phosphate buffer over a range of sodium and phosphate concentrations ( $0.01 \mathrm{M}$ to $0.8 \mathrm{M}$ and $0.02 \mathrm{M}$ to $0.2 \mathrm{M}$, respectively). During all dissolution testing, a constant stirring speed and temperature were maintained at $200 \mathrm{rpm}$ and $37^{\circ} \mathrm{C}$, respectively. Changes in the absorbance values at $235 \mathrm{~nm}$ were recorded for $20 \mathrm{mi}-$ nutes at two-minute intervals. Results are replicated ( $n=6)$ for statistical analysis, and a mean value for absorbance was then calculated to obtain the percentage of drug released for each time interval. It should be noted that before drug release experiments, it was found that the presence of the drug and/or microspheres did not affect the $\mathrm{pH}$ of the dissolution media under any conditions investigated in this research. A solution of $\mathrm{pH} 8$ was chosen to optimize the solubility of the drug ${ }^{62,64}$. Various limitations relating to atmosphere, edaphic, generation, and innovation viewpoints as specified underneath frustrates higher efficiency ${ }^{66}$.

\section{Angle Of Repose}

Firstly, measure the height (h) of the microsphere pile from the ground's peak ${ }^{64}$. Then measured the horizontal distance (d) from the middle of the pile to the edge. Then use the formula

Angle of Repose $=\tan ^{-1}(2 \mathrm{~h} / \mathrm{d})$

\section{Bulk Density and Tapped Density}

The bulk density is received by adding a regarded powder mass to a graduated cylinder. The taped density is obtained by robotically tapping a graduated cylinder containing the microspheres until little similar volume change is determined. The tapped density is calculated as mass divided with the aid of the very last volume of the powder ${ }^{67,68}$.

\section{Swelling study (degree of swelling)}

Microspheres (one hundred $\mathrm{mg}$ ) had been positioned in a little extra distilled water, 0.1N HCl, and PBS ( $\mathrm{pH} 7$. four) and allowed to swell to consistent weight. The microspheres were separated and blotted with filter paper, and their modifications in weight modifications had been computed at a c program language length of 10 minutes and recorded. The diploma of swelling (A) changed into then calculated from the components: $A=W g-W O / W O$ in which Wo is the preliminary weight of the beads, and $\mathrm{Wg}$ is the burden of the beads at equilibrium swelling within the medium $53,54,64,69$.

\section{Percentage Yield}

The prepared microspheres were wholly dried in an oven maintained at $37^{\circ} \mathrm{C}$ for 24 hours and then weighted $d^{54,64,69}$. The percentage yield of microspheres was calculated according to the following equation: \% Yield $=($ Practical Yield $/$ Theoretical Yield) ${ }^{*} 100$

\section{Discussion}

This review article reflects upon the ionotropic gelation technique of Microsphere formulation. Future possible advancements with microsphere drug delivery were based on the information and knowledge; progress is possible. An individual should enrich the knowledge of different subjects. The more people gain knowledge, the more contribution can be expected to this subject ${ }^{70}$. A microsphere is a process in which drug particles can be encapsulated in a biodegradable polymer or a synthetic polymer that can be used as a delivery system. A controlled or sustained drug delivery system or insoluble drugs has become a significant concern for all in the pharmaceutical field because of its expenses, time-consuming, and development process ${ }^{71,72}$. In this pharmaceutical field, the microsphere plays a significant role where different kinds of problems can be solved quickly, such as it can be used to increase the bio-availability of the highly insoluble drugs in nature ${ }^{21}$. In the pharmaceutical measurements shapes that contain it as one of a kind dynamic standard with very productive outcomes for the particular motivations behind its outline ${ }^{73}$.

Cancer is considered a common disease in the whole world. Currently, chemotherapy is considered one of the most common treatments by almost all doctors in this situation. HER2, human epidermal growth factor 2, is a marker for breast cancer that is overexpressed by 25\% - 30\% for invasive breast cancers. Anti-cancer drugs loaded with albumin microsphere can show the effect against human epidermal growth factor 2 (HER2) and a relatively new type of "targeted" cancer therapy for breast cancer treatment ${ }^{74,75}$. These assumptions may seem restrictive, but they are satisfied for many natural systems, and in any case, the resulting expressions yield invaluable insights $^{76}$.

In this fast living world, we find discoveries of different kinds of drugs almost every day that lead to more effective results. Every drug has its gains and drawbacks; working with a microsphere can open many different sections to deal with the drugs that possess different kinds of problems. Researchers are working hard for more betterment of this work, and betterment is such a process that shall be ever-growing ${ }^{77}$. Above mentioned suggestions, recommendations, research depend on our statistical surveying, which is restricted as far as anyone is concerned, and capacity and the discoveries from this investigation are probably going to factor unequivocally into essential arranging ${ }^{78}$.

On the other hand, vaccines are considered one of the most efficient and inexpensive ways to immunize and control infectious diseases. The dose of the vaccine can be encapsulated by a layer of polymer or a biodegradable polymer, which in turn helps in the controlled release of the antigen in the body, and therefore the multiple dosage forms of the vaccine can be reduced as low as a single dosage form ${ }^{79}$. More studies are required in this field for a better palliative approach. Compartment displaying is broadly utilized and a matter of worry in restorative sciences ${ }^{80}$.

\section{Conclusions}

Microspheres (Few Lab Prepared Microspheres is given in Fig No. 6.) are characteristically free-flowing powders having a particle size starting from 1-1000 $\mu \mathrm{m}$ consisting of proteins or synthetic polymers where the range of techniques for the preparation of microspheres provides multiple options to regulate as drug administration aspects and to reinforce the 


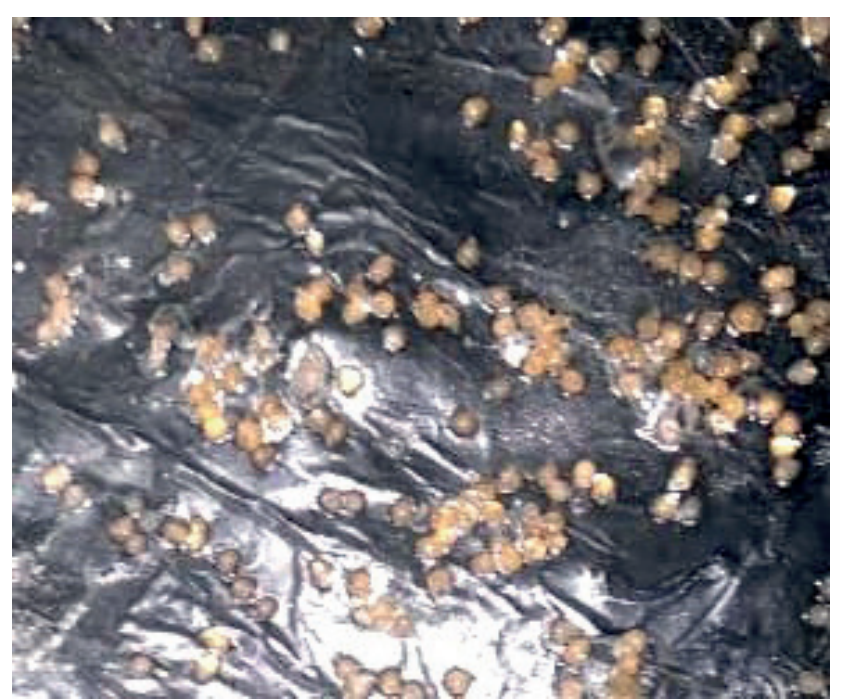

Figure 6. Few Lab Prepared Microspheres.

therapeutic efficacy of a given the drug. Although there is a variety of difficulties to be figured out to achieve prolonged gastric retention, an excessive number of companies are that specializes in commercializing this system due to their advantages of sustained and controlled-release action, reduced dose frequency, improved steadiness, dissolution rate, and bioavailability the microspheres drug delivery system is that the hottest drug delivery system. Compared to standard dosage forms, these delivery systems offer numerous advantages, including improved efficacy, reduced toxicity, improved patient compliance, and convenience. Such systems frequently use macromolecules as carters for the drugs. Microspheres by ionotropic gelation technique promise a possible approach for gastric retention. By combining various other strategies, within the future, the microspheres will find a prominent \& central place within the novel drug delivery, particularly within the diagnostics, diseased cell sorting, gene \& genetic materials, targeted, safe, effective \& specific in vitro delivery \& supplements because the miniature versions of the diseased tissues \& organ within the body.

\section{Author Contributions}

Anirban Karmakar: Literature Review \& Investigation, Writing - Original Draft Preparation \& corresponding author. Soumya Dev Maity: Software, Editing, Correction, Software and other essentials. Raneet Das: Data Curator, Acquiring Permissions, Visualization, Writing - Reviewing and Editing. Shayeree Barua: Writing - Reviewing and Editing, Reformatting.

\section{Funding}

Authors declare no such funding related to this article.

\section{Acknowledgments}

The authors are very thankful to Suprodip Mandal (Assistant Professor, Department Of Pharmacognosy, School Of Pharmacy, Techno India University, Salt Lake Sec-V, Kolkata) for his professional devotion vigor and his guidance during this project.

\section{Conflicts of Interest}

Authors do not claim any conflict of interest.

\section{Bibliographic references}

1. Devi J, Muthu AK. Isolation and characterization of active components derived from whole-plant of Saccharum spontaneum (linn.). 2015;7:197-203.

2. Kramer PA. Albumin Microspheres as Vehicles for Achieving Specificity in Drug Delivery. Journal of Pharmaceutical Sciences. 1974;63(10):1646-1647. doi:10.1002/jps.2600631044

3. Singh MN, Hemant KSY, Ram M, Shivakumar HG. Microencapsulation: A promising technique for controlled drug delivery. Res Pharm Sci. 2010;5(2):65-77.

4. Nikam PM, Gondkar SB, Saudagar RB. Nanocrystal Drug Delivery System: A Review. Rese Jour Pharmaceut Dosag Form and Technol. 2016;8(2):122. doi:10.5958/0975-4377.2016.00016.1

5. Padalkar DrA, Shahi S, Thube patil M. Micro particles: An approach for betterment of drug delivery system. International Journal of Pharma Research and Development - Online. 2011;3:March/012.

6. Bidyut Das, Juti Rani Devi. MICROPARTICULATE DRUG DELIVERY SYSTEM- A REVIEW. World Journal of Pharmaceutical and Life Sciences WJPLS. 2(6):243-258.

7. Bharath S. Pharmaceutical Technology: Concepts and Applications. Pearson Education India; 2013. Accessed June 10, 2021. https://books.google.co.in/books?id=akQ8BAAAQBA$J \& p g=P A 189 \& l p g=P A 189 \& d q=\% 22$ Microcapsules+are+systems+in+which+the+drug+is+confined+to+a+cavity+surrounded+by+a+unique+polymer+membrane.\%22\&source $=$ bl \&ots $=I C K J p 050 \mathrm{Jb} \& \mathrm{sig}=\mathrm{ACfU} 3 \cup 2 \mathrm{lIR} 3 \mathrm{TVZ}$ 3CYMWxMG5y66vlGjVfAw\&hl=en\&sa=X\&ved=2ahUKEwiQ1orJzYTwAhXs7HMBHdphD5QQ6AEwAnoECAEQAw\#v=onepage$\& q \& f=f a l s e$

8. Drx Rather Ishfaq. microparticulate drug delivery system ppt. Presented at the: 04:10:21 UTC. Accessed June 10, 2021. https:// www.slideshare.net/DrxRatherlshfaq/ishfaq-ahmad-rather-power-presentation

9. Saha A, Debnath B. The obscure impact of Nipah virus. RB. 2019;4(1). doi:10.21931/RB/2019.04.01.13

10. Spain SG, Yaşayan G, Soliman M, Heath F, Saeed AO, Alexander C. Nanoparticles for Nucleic Acid Delivery. In: Comprehensive Biomaterials. Elsevier; 2011:389-410. doi:10.1016/B978-0-08055294-1.00133-1

11. Gupta P, Vermani K, Garg S. Hydrogels: from controlled release to $\mathrm{pH}$-responsive drug delivery. Drug Discovery Today. 2002;7(10):569-579. doi:10.1016/S1359-6446(02)02255-9

12. study of microparticle preparation by the solvent evaporation method using focused beam reflectance measurement (fbrm) - pdf free download. accessed june 10, 2021. https://docplayer. net/29309088-Study-of-microparticle-preparation-by-the-solvent-evaporation-method-using-focused-beam-reflectance-measurement-fbrm.html

13. Saha A, Chatterjee A, Chowdhury S. An Overview on the Role of Transcription in Medical and Computer Application. CiiT International Journal of Artificial Intelligent Systems and Machine Learning. 2018;10(10):230-238. doi:AIML102018004

14. BankarS.K, Chaudhari A.V, Mahale N.B, Chaudhari S.R. A Review on Orodispersible Tablets Prepared Using Spray Dried Sustained Release Microparticles. JADD. 1(2):82-95.

15. Saha A, Bhattachajee S, Mukherjee S. Research and Review: Drugs and Drugs Development Based on Protein Drug Delivery System. Research and Advances in Pharmacy and Life Sciences. 2019;1(1):1-13. doi:http://doi.org/10.5281/zenodo.1

16. Saha A, Chatterjee A, Ghosh M. An Overview On The Utility Of Computer Application In The Pharmacy World And Its Significance. IRJPS. 2018;5(3):1628-1635. doi:10.21276/irjps.2018.5.3.9

17. Saha A, Debnath B. Research And Review: Drugs And Drugs Development Based On Novel Drug Delivery System. Research \& Review: Drugs and Drugs Development. 2018;1(1):1-13. doi:10.5281/ZENOD0.1477186

18. Hennink WE, van Nostrum CF. Novel cross-linking methods to design hydrogels. Advanced Drug Delivery Reviews. 2002;54(1):1336. doi:10.1016/S0169-409X(01)00240-X 
19. Sharma J, Kalra S, Sharma A, Rani S. Colloidal Drug Carriers. The Internet Journal of Family Practice. 2009;9(2). Accessed June 10, 2021. http://ispub.com/lJFP/9/2/10130

20. Recent Advances in Novel Drug Delivery Systems. AZoNano. com. Published March 25, 2006. Accessed June 10, 2021. https:// www.azonano.com/article.aspx?ArticlelD $=1538$

21. Tiwari G, Tiwari R, Sriwastawa B, et al. Drug delivery systems: An updated review. Int J Pharm Investig. 2012;2(1):2-11. doi:10.4103/2230-973X.96920

22. Kabiri K, Omidian H, Hashemi SA, Zohuriaan-Mehr MJ. Synthesis of fast-swelling superabsorbent hydrogels: effect of cross-linker type and concentration on porosity and absorption rate. European Polymer Journal. 2003;39(7):1341-1348. doi:10.1016/S00143057(02)00391-9

23. Kotturi N. Research and Reviews: Journal of Pharmaceutics and Nanotechnology. 2015;3(2):4.

24. Ahmed EM. Hydrogel: Preparation, characterization, and applications: A review. Journal of Advanced Research. 2015;6(2):105121. doi:10.1016/j.jare.2013.07.006

25. Singh A, Garg G, Sharma P. NANOSPHERES: A NOVEL APPROACH FOR TARGETED DRUG DELIVERY SYSTEM. 5(3):5.

26. novel drug delivery system. vibdoc.com. Accessed June 10, 2021. https://vibdoc.com/novel-drug-delivery-system.html

27. Surabhi Mehra, Ashok Kumar, Shamsher S Kanwar. Synthesis of an Antioxidant n-propyl Gallate by Magnetic Iron Nanoparticles-bound Lipolase. Research \& Reviews: Journal of Pharmaceutics and Nanotechnology.

28. Drug Release - an overview I ScienceDirect Topics. Accessed June 10, 2021. https://www.sciencedirect.com/topics/nursing-and-health-professions/drug-release

29. Alvarez-Lorenzo C, Concheiro A. Reversible adsorption by a $\mathrm{pH}-$ and temperature-sensitive acrylic hydrogel. Journal of Controlled Release. 2002;80(1-3):247-257. doi:10.1016/S01683659(02)00032-9

30. Hadpad Shobha, Jadhav Shital. Microspheres - a novel drug delivery system. 1. Accessed June 10, 2021. https://www.ejbps.com/ ejbps/abstract_id/5821

31. B. Sree Giri Prasad, V. R. M Gupta, N. Devanna, K. Jayasurya. MICROSPHERES AS DRUG DELIVERY SYSTEM - A REVIEW. Journal of Global Trends in Pharmaceutical Sciences. Accessed June 10, 2021. https://1library.net/document/yrk5lOjz-microspheres-as-drug-delivery-system-a-review.html

32. Midha K, Nagpal M, Arora S. Microspheres: a recent update. International Journalof Recent ScientificResearch. 2015;6(8).

33. Byrne ME, Park K, Peppas NA. Molecular imprinting within hydrogels. Advanced Drug Delivery Reviews. 2002;54(1):149-161. doi:10.1016/S0169-409X(01)00246-0

34. Acharya A, Mohan H, Sabharwal S. Radiation induced polymerization and cross-linking behavior of N-hydroxy methyl acrylamide in aqueous solutions. Radiation Physics and Chemistry. 2002;65(3):225-232. doi:10.1016/S0969-806X(02)00271-2

35. Saha A, Das M, Das A, Mandal S. Dietetic Benefits of Yogurt Based Beverage (Lassi) Becoming Fact-Finding Probe in Research. IJPR. 2021;13(03):1150-1156. doi:10.31838/ijpr/2021.13.03.157

36. Ganesan P, Deepa John AJ, Sabapathy L, Duraikannu A. Review on Microsphere. American J of Drug Discovery and Development. 2014;4(3):153-179. doi:10.3923/ajdd.2014.153.179

37. A.G. Chintale, V.S. Kadam, K.S. Maske, D.B. Raut, S.V. Kale, S.D. Rai. Recent Advances in Microsphere Drug Delivery System: A Review. Accessed June 10, 2021. https://rjptonline.org/HTML Papers/Research\%20Journal\%20of\%20Pharmacy\%20and\%20 Technology_PID_2013-6-4-11.html

38. Gavali KV, Kengar MD, Chavan KV, Anekar VP, Khan NI. A Review on Microsphere and it's Application. Asian Jour Pharmac Rese. 2019;9(2):123. doi:10.5958/2231-5691.2019.00020.0

39. Chandna A, Batra D, Kakar S, Singh R. A review on target drug delivery: magnetic microspheres. Journal of Acute Disease. 2013;2(3):189-195. doi:10.1016/S2221-6189(13)60125-0

40.Hamad Farah F. Magnetic Microspheres: A Novel drug delivery system. japlr. 2016;3(4). doi:10.15406/japlr.2016.03.00067
41. chitra singh, suresh purohit, madhu singh, b.l.pandey. design and evaluation of microspheres:a review. journal of drug delivery research. 2(2). Accessed June 10, 2021. https://www.academia. edu/5260698/Design_and_evaluation_of_microspheres_a_review

42. Pal K, Banthia AK, Majumdar DK. Preparation and characterization of polyvinyl alcohol-gelatin hydrogel membranes for biomedical applications. AAPS PharmSciTech. 2007;8(1):21. doi:10.1208/pt080121

43. Kaushik A, Tiwari A, Gaur A. Role of excipients and polymeric advancements in preparation of floating drug delivery systems. Int J Pharma Investig. 2015;5(1):1. doi:10.4103/2230-973X.147219

44. Tarun Virmani, Jyoti Gupta. Pharmaceutical application of microspheres: an approach for the treatment of various diseases. ijpsr. 8(8). doi:10.13040/ijpsr.0975-8232.8(8).3252-60

45.Mukund JY, Kantilal BR, Sudhakar RN. Floating microspheres: a review. Braz J Pharm Sci. 2012;48(1):17-30. doi:10.1590/S198482502012000100003

46. Horii F, Hu S, Ito T, et al. Cross polarization/magic angle spinning $13 \mathrm{C}$ n.m.r. study of solid structure and hydrogen bonding of poly(vinyl alcohol) films with different tacticities. Polymer. 1992;33(11):2299-2306. doi:10.1016/0032-3861(92)90520-7

47. Manoj kumar das, abdul baquee ahmed, dipankar saha. microsphere a drug delivery system-a review. international journal of current pharmaceutical research. 11(4):34-41.

48. Manish Jamini, Saurabh Rawat. A Review on Microsphere. Research Journal of Pharmaceutical, Biological and ChemicalSciences. 4(1). Accessed June 10, 2021. https://www.academia. edu/6790961/A_Review_on_Microsphere

49.Desai KG. Chitosan Nanoparticles Prepared by lonotropic Gelation: An Overview of Recent Advances. Crit Rev Ther Drug Carrier Syst. 2016;33(2):107-158. doi:10.1615/CritRevTherDrugCarrierSyst.2016014850

50.Ganesh N. S., G.Bharathi, Hanumanthachar Joshi, Jayanthi C, Devendra Pratap Singh. buoyant multiparticulate drug delivery - a focus onhydrogel beads. woorrlldd j joouurrnnaall ooff pphhaarrmmaacc y y aanndd pphhaarrmmaacceeuuttiiccaall sscciieenncceess. 2(2). accessed june 10, 2021. https://www.academia. edu/5741871/buoyant_multiparticulate_drug_delivery_a_focus_ on_hydrogel_beads_wjpps?auto=download

51. j.s. patil, m.v. kamalapur, s.c. marapur, d.v. kadam. ionotropic gelation and polyelectrolyte complexation: the novel techniques to design hydrogel particulate sustained, modulated drug delivery system: a review. digest journal of nanomaterials and biostructures. 5(1):241-248.

52. Peppas NA, Merrill EW. Development of semicrystalline poly(vinyl alcohol) hydrogels for biomedical applications. J Biomed Mater Res. 1977;11(3):423-434. doi:10.1002/jbm.820110309

53. Mahale MM, Saudagar RB. Microsphere: A Review. Journal of Drug Deli very \& Therapeutics. 2019;9(3-s):854-856. doi:http:// dx.doi.org/10.22270/jddt.v9i3

54.NR K. Microsphere: A Brief Review. AJBPS. 2015;05(47):13-19. doi:10.15272/ajbps.v5i47.713

55. Patil NV, Wadd NV, Thorat SS, Upadhye SS. Microspheres: A Novel Drug Delivery System. Am J PharmTech Res. 2020;10(02):286-301.

56. Oakenfull D, Scott A. Gelatin gels in deuterium oxide. Food Hydrocolloids. 2003;17(2):207-210. doi:10.1016/S0268005X(02)00053-X

57. Ajaykumar Tiwari, Gaurang Patel, Nirav Rabadia. FORMULATION AND EVALUATION OF FLOATING MICROSPHERE H2RECEPTOR BLOCKER RANITIDINE HCIBY IONIC GELATION METHOD. International Journal Of Pharmaceutical Sciences And Research. 3. Accessed June 10, 2021. https://1library.net/document/zkeljxlz-formulation-evaluation-floating-microsphere-receptor-blocker-ranitidine-gelation.html

58. Syed Ershad, V Sai Kishore, U Kartheek, M Sandeep, K Prameela Rani, K Adithya. Preparation and Evaluation of Floating Microspheres of Ritonavir. Research And Reviews:Journal Of Pharmacy And Pharmaceutical Sciences. 2013;3(1). Accessed June 10, 2021. https://www.rroij.com/open-access/preparation-and-evaluation-of-floating-microspheres-of-ritonavir-5-11.pdf 
59.Pal K, Pal S. Development of Porous Hydroxyapatite Scaffolds. Materials and Manufacturing Processes. 2006;21(3):325-328. doi:10.1080/10426910500464826

60.Rinku khurana, Alka Ahuja, Roop K. Khar. Development And Evaluation of Mucoadhesive Films Of Miconazole Nitrate. Indian Journal Of Pharmaceutical Sciences. Accessed June 11, 2021. https:// ijpsr.com/bft-article/buccal-patches-a-review/?view=fulltext

61. BC Behera, SK Sahoo, S Dhal, BB Barik, BK Gupta. Characterization Of Glipizide-Loaded Polymethacrylate Microspheres Prepared By An Emulsion Solvent Evaporation Method. Tropical Journal of Pharmaceutical Research. 7. Accessed June 10, 2021. http://www.bioline.org.br/request?pr08003

62. Pal K, Banthia AK, Majumdar DK. Development of carboxymethyl cellulose acrylate for various biomedical applications. Biomed Mater. 2006;1(2):85-91. doi:10.1088/1748-6041/1/2/006

63. Yaswanth Allamneni, B V V K Reddy, P Dayananda Chary, Venkata Balakrishna Rao N, S Chaitanya Kumar, Arun Kumar Kalekar. Performance Evaluation of Mucoadhesive Potential of Sodium Alginate on Microspheres Containing an Anti-Diabetic Drug: Glipizide. International Journal of Pharmaceutical Sciences and Drug Research::115-122

64. Mazumder R, Allamneni Y, Firdous SM, Parya H, Chowdhury AD. Formulation, development and in-vitro release effects of ethylcellulose coated pectin microspheres for colon targeting. Asian $J$ Pharm Clin Res. 2013;6(5):138-144.

65. Ramana G, Krishna Chaitanya A. Preparation and In-vitro characterization of ethylcellulose coated pectin alginate microspheres of 5-fluorouracil for colon targeting. Journal Of Applied Pharmaceutical Science. Accessed June 10, 2021. https://1library.net/ document/yn4e6rjz-journal-of-applied-pharmaceutical-science. html

66. Saha A, Mandal S. Nutritional Benefit of Soybean and Its Advancement in Research. SFP. 2019;5:6-16. doi:10.18052/www. scipress.com/SFP.5.6

67. Bulk and Tapped Density. Particle Analytical. Accessed June 10, 2021. https://particle.dk/methods-analytical-laboratory/bulkand-tapped-density/

68. Falk B, Garramone S, Shivkumar S. Diffusion coefficient of paracetamol in a chitosan hydrogel. Materials Letters. 2004;58(26):3261-3265. doi:10.1016/j.matlet.2004.05.072
69. Sharma N, Purwar N, Gupta PC. MICROSPHERES AS DRUG CARRIERS FOR CONTROLLED DRUG DELIVERY: A REVIEW. IJPSR. 2015:6(12):4579-4587. doi:10.13040/ IJPSR.0975-8232.6(11).4579-87

70. Saha A, Das A, Mandal S. Reading Journals of Different Spectrum: Necessities and Importance. IJNHS. 2021;2(1):1-4.

71. Ju X-J, Chu L-Y. Lab-on-a-chip fabrication of polymeric microparticles for drug encapsulation and controlled release. In: Microfluidics for Pharmaceutical Applications. Elsevier; 2019:217-280. doi:10.1016/B978-0-12-812659-2.00009-0

72. Kakkar V, Wani SUD, Gautam SP, Qadrie ZL. ROLE OF MICROSPHERES IN NOVEL DRUG DELIVERY SYSTEMS: PREPARATION METHODS AND APPLICATIONS. Int J Curr Pharm Sci. Published online May 15, 2020:10-15. doi:10.22159/ijcpr.2020v12i3.38326

73. Saha A, Jana M, Das A. Comparative In Vitro Evaluation Of Two Commercially Available Brands Of Pantoprazole And Domperidone Capsules. IRJPS. 2018;5(2):1500-1505. doi:10.21276/irjps.2018.5.2.13

74. Rajput M. Agrawal P. Microspheres in cancer therapy. Indian J Cancer. 2010;47(4):458. doi:10.4103/0019-509X.73547

75. King J, Quinn R, Glenn DM, et al. Radioembolization with selective internal radiation microspheres for neuroendocrine liver metastases. Cancer. 2008;113(5):921-929. doi:10.1002/cncr.23685

76. Saha A, Bhattacharjee S. Research and Review: Based on Distillation, Distillation Types and Advancements: A Short Summary. Journal of Advances in Pharmacy Practices. 2019;1(1):8-16. doi:10.5281/ZENODO.2545018

77. Jana M, Mandal S, Das A, Das M, Saha A. Granulation strategy holding a dynamic rhythm in herbal pharmaceuticals. PHARMAWAVE. 2020;13:9-24

78. Saha A, Das A, Dutta S, Mandal S. A Competitive Analysis Of Top Ten Pharmaceutical Companies In India. RB. 2021;6(2):18651872. doi:10.21931/RB/2021.06.02.30

79. Eldridge JH, Staas JK, Meulbroek JA, McGhee JR, Tice TR, Gilley RM. Biodegradable microspheres as a vaccine delivery system. Molecular Immunology. 1991;28(3):287-294. doi:10.1016/01615890(91)90076-V

80. Saha A, Bhattacharjee S, Jana M, Mandal S. Research And Review: Advancement In The Pharmacokinetics Of One Compartment Modeling. IJNHS. 2020;1(2):7-18. 